\title{
O INHANDUVÁ (PROSOPIS AFFINIS SPRENG.) NO RIO GRANDE DO SUL. 3 - PARQUE DA CABANHA DO LORETO, SÃO VICENTE DO SUL ${ }^{1}$
}

\author{
JOSÉ NEWTON CARDOSO MARCHIORI² FABIANO DA SILVA ALVES ${ }^{3}$ \\ EDUARDO ALONSO PAZ ${ }^{4}$
}

\section{RESUMO}

A ocorrência natural de inhanduvá (Prosopis affinis Spreng., Fabaceae) é presentemente estendida ao município de São Vicente do Sul (Rio Grande do Sul - Brasil), com a presente descrição de um parque existente no topo de uma colina de solos arenosos, com blocos de rochas, próxima ao rio Jaguari.

Palavras-chave: Prosopis affinis, Fitogeografia, São Vicente do Sul, Rio Grande do Sul.

\section{SUMMARY}

[Prosopis affinis Spreng. in Rio Grande do Sul state, Brazil. 3 - Natural occurrence in the municipality of São Vicente do Sul].

The occurrence of Prosopis affinis Spreng. (Fabaceae) is presently extended to the municipality of São Vicente do Sul (Rio Grande do Sul state-Brazil), due the present description of a natural stand found on the top of a sand hill, with small rocks, close to Jaguari river.

Keywords: Prosopis affinis, Phytogeography, São Vicente do Sul, Rio Grande do Sul state - Brazil.

\section{INTRODUÇÃO}

Tema controvertido, a distribuição geográfica do inhanduvá (Prosopis affinis Spreng.) apresenta duas correntes divergentes na literatura sul-rio-grandense, havendo autores que referem, para a espécie, uma área restrita aos arredores de Barra do Quaraí e outros que postulam uma distribuição mais ampla, no centrooeste do Estado. Entre os primeiros, Galvani (2003) chega afirmar, nas "Considerações Finais" de sua Tese de Doutorado ${ }^{5}$, que a área do

1 Recebido em 30-7-2010 e aceito para publicação em 25-10-2010.

2 Engenheiro Florestal, Dr. Professor Titular do Departamento de Ciências Florestais, UFSM. Bolsista de Produtividade em Pesquisa ( $\mathrm{CNPq}$ - Brasil).

3 Biólogo, MSc. Doutorando do Programa de Pós-Graduação em Engenharia Florestal - UFSM. Professor da Universidade da Região da Campanha - URCAMP (Alegrete, RS).

4 Biólogo, Professor de Botânica na Faculdade de Química. Universidad de la Republica, Montevideo - Uruguai.

5 GALVANI, F.R. Vegetação e aspectos ecológicos do Parque Estadual do Espinilho, Barra do Quaraí, RS. Porto Alegre: Universidade Federal do Rio Grande do Sul, 2003.132f. Tese de Doutorado (Programa de PósGraduação em Botânica).
Parque Estadual do Espinilho constitui "o único ambiente de ocorrência de Prosopis affinis Griseb. e Prosopis nigra (Gris.) Hieron. no Estado do Rio Grande do Sul e no Brasil"“. Entre os que postulam uma área de ocorrência mais ampla, incluem-se: Veloso \& Góes-Filho (1982), Marchiori et al. (1983, 1985) e Marchiori (2004).

De acordo com Veloso \& Góes-Filho (1982), o inhanduvá limita-se a solos aluviais próximos ao rio Uruguai, de Barra do Quaraí até Uruguaiana $^{7}$. Marchiori et al. $(1983,1985)$ referem a ocorrência em "pontos isolados da Campanha do Sudoeste, notadamente ao longo da bacia do rio Ibicuî". Marchiori (2004), por sua vez, assinala a presença da espécie em alguns pontos da bacia do Ibicuí, inclusive no "município de São Vicente do Sul, sempre associado a depósitos aluviais" 8 .

6 GALVANI, 2003. Op. cit., p. 87.

7 VELOSO, H.B.; GÓES-FILHO, L. Fitogeografia brasileira - Classificação fisionômico-ecológica da vegetação neotropical. Salvador: Projeto RADAMBRASIL, 1982. 80 p. (Boletim Técnico, Ser. Vegetação, v. 1).

${ }^{8}$ MARCHIORI, J.N.C. Fitogeografia do Rio Grande do Sul. Campos sulinos. Porto Alegre: EST, 2004. p. 63. 
Em publicação recente, Marchiori \& Alves (2010) abordam questões fitogeográficas e terminológicas relativas ao inhanduvá, fornecendo um embasamento para a investigação mais aprofundada do tema. Em artigo posterior, Alves \& Marchiori (2010) comprovaram a ocorrência natural do inhanduvá no interior do município de Quaraí, em lente de solos arenosos próxima à encosta sul dos cerros do Jarau, com base em elementos florísticos, da estrutura vegetacional e em documentos históricos.

No presente trabalho, que visa a lançar novos olhares sobre o parque de inhanduvá existente em São Vicente do Sul - e referido apenas de passagem, em publicação anterior ${ }^{9}$-, esta singularidade vegetacional é analisada sob diferentes enfoques, com vistas à comprovação de sua origem natural.

\section{DESCRIÇÃO DO PARQUE DE INHAN- DUVÁ}

Conhecido pelo primeiro autor desde setembro de $1982^{10}$, o parque de inhanduvá de São Vicente do Sul é presentemente investigado com vistas ao registro de sua ocorrência e ao esclarecimento de sua origem.

Situado no topo de suave coxilha, na Cabanha do Loreto, município de São Vicente do Sul, os inhanduvás podem ser vistos da rodovia RS 241, no trecho entre o Cerro do Loreto e o rio Jaguari, pois ficam cerca de $1,5 \mathrm{~km}$ ao sul da referida estrada (Figura 1). O local, definido pelas coordenadas de $29^{\circ} 42^{\prime} 13^{\prime \prime} \mathrm{S}$ e $54^{\circ}$ $56^{\prime} 05^{\prime \prime} \mathrm{O}$, encontra-se a $125 \mathrm{~m}$ de altitude, distando $2,3 \mathrm{~km}$ a leste do rio Jaguari, $3,3 \mathrm{~km}$ a sudoeste do Cerro do Loreto e cerca de $9 \mathrm{~km}$ a norte do rio Ibicuí. O solo da região, definido como Argissolo Bruno Acinzentado (Streck et

9 MARCHIORI, 2004. Op. cit., p. 63.

${ }^{10} \mathrm{Em} 22$ de setembro de 1982, o parque de inhanduvá foi visitado, pela primeira vez, por José Newton Cardoso Marchiori, Solon Jonas Longhi e Luiz Galvão. Como as árvores estavam estéreis, não foram feitas coletas botânicas da espécie na ocasião. al., 2008), apresenta afloramento de pequenos blocos de rocha, junto aos inhanduvás.

A vegetação, com estrutura de parque, reúne cerca de 50 inhanduvás adultos no estrato arbóreo, sem espaçamento regular e com alturas e diâmetros variados (Figura 2), destacando-se alguns indivíduos de dimensões notavelmente avantajadas para a espécie (Figura 3 ). No estrato herbáceo, muito prejudicado pelo pisoteio do gado, que busca a vegetação como abrigo, salienta-se a ausência do capim-caninha (Andropogon lateralis Nees) e do alecrim-docampo (Vernonia nudiflora Lessing) à sombra dos inhanduvás, espécies dominantes no campo circunjacente, juntamente com a gramaforquilha (Paspalum notatum Flüegge), o pegapega (Desmodium incanum DC.), o bibi (Herbertia lahue (Molina) Goldblatt), além de uma espécie de caraguatá (Eryngium sp.). A presença abundante do capim-anoni (Eragrostis plana Nees), da guanxuma (Sida rhombifolia L.) e da roseta (Soliva sessilis Ruiz \& Pav.), por sua vez, revelam intenso antropismo na vegetação campestre. Das epífitas, destacam-se: Rhipsalis lumbricoides (Lem.) Lem., cactácea abundante, sobretudo nos inhanduvás mais velhos, três cravos-do-mato (Tillandsia aëranthos (Loiseleur) L.B. Smith; Tillandsia recurvata L.; Tillandsia tricholepis Baker), três pteridófitas (Microgramma mortoniana de la Sota; Pleopeltis pleopeltifolia (Raddi) Alston; Pleopeltis squalida (Vell.) de la Sota) e uma orquídea (Oncidium bifolium Sims).

Comparado com outras ocorrências naturais de inhanduvá no Estado, chama atenção, na estrutura do parque, a ausência de outros elementos chaquenhos, como o espinilho (Vachellia caven (Mol.) Seigler \& Ebinger), o algarrobo (Prosopis nigra (Griseb.) Hieron.), o quebracho (Aspidosperma quebrachoblanco Schltdl.), a cina-cina (Parkinsonia aculeata L.), bem como da arumbeva-de-flores-alaranjadas (Opuntia elata Salm Dick) e de dois cravos-do-mato (Tillandsia duratii Visiani e Tillandsia ixioides Griseb.). 


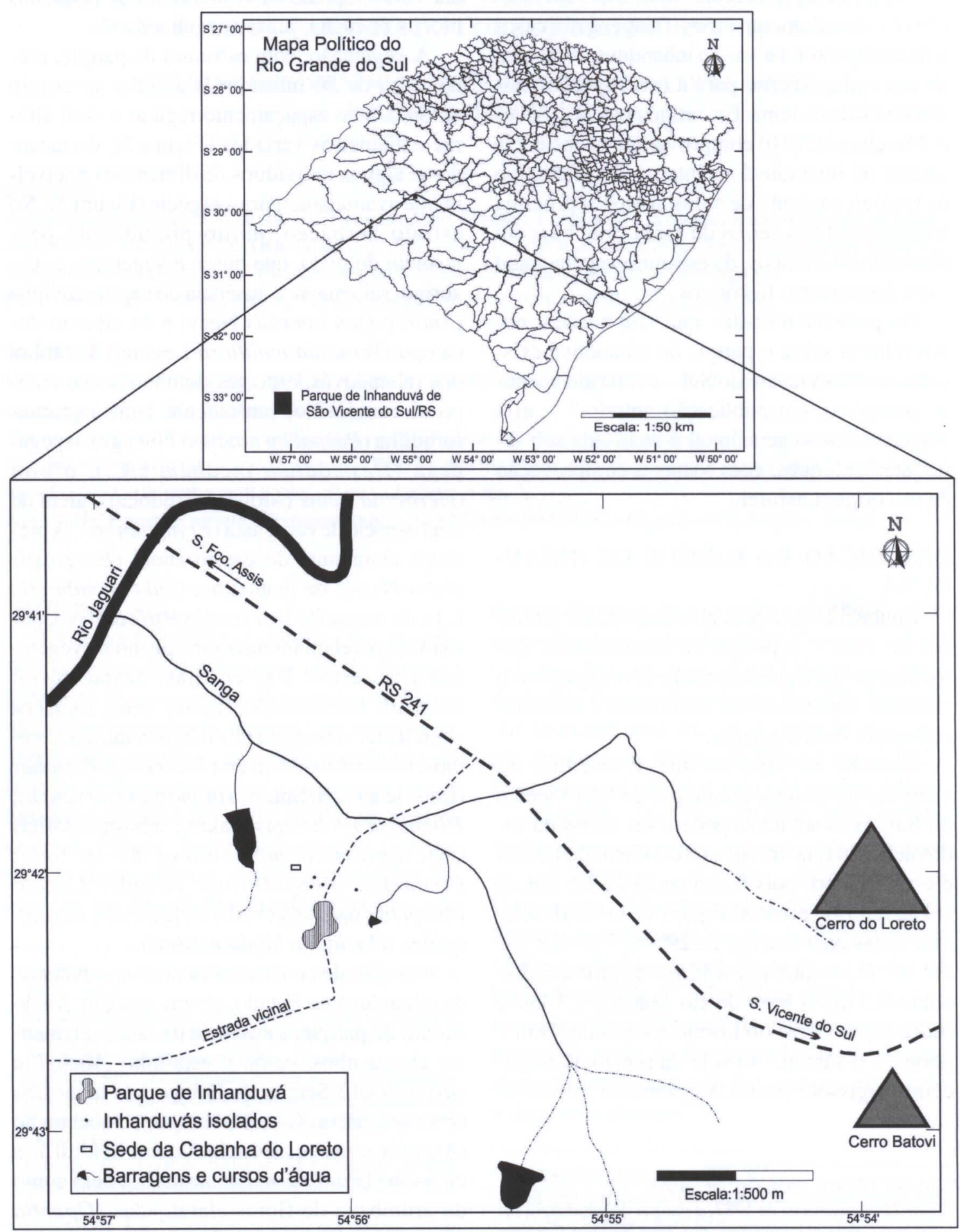

FIGURA 1 - Mapa de localização do Parque de Inhanduvá da Cabanha do Loreto. (Elaborado com base em mapas interativos do IBGE e imagens de satélite Google Earth 2010). 

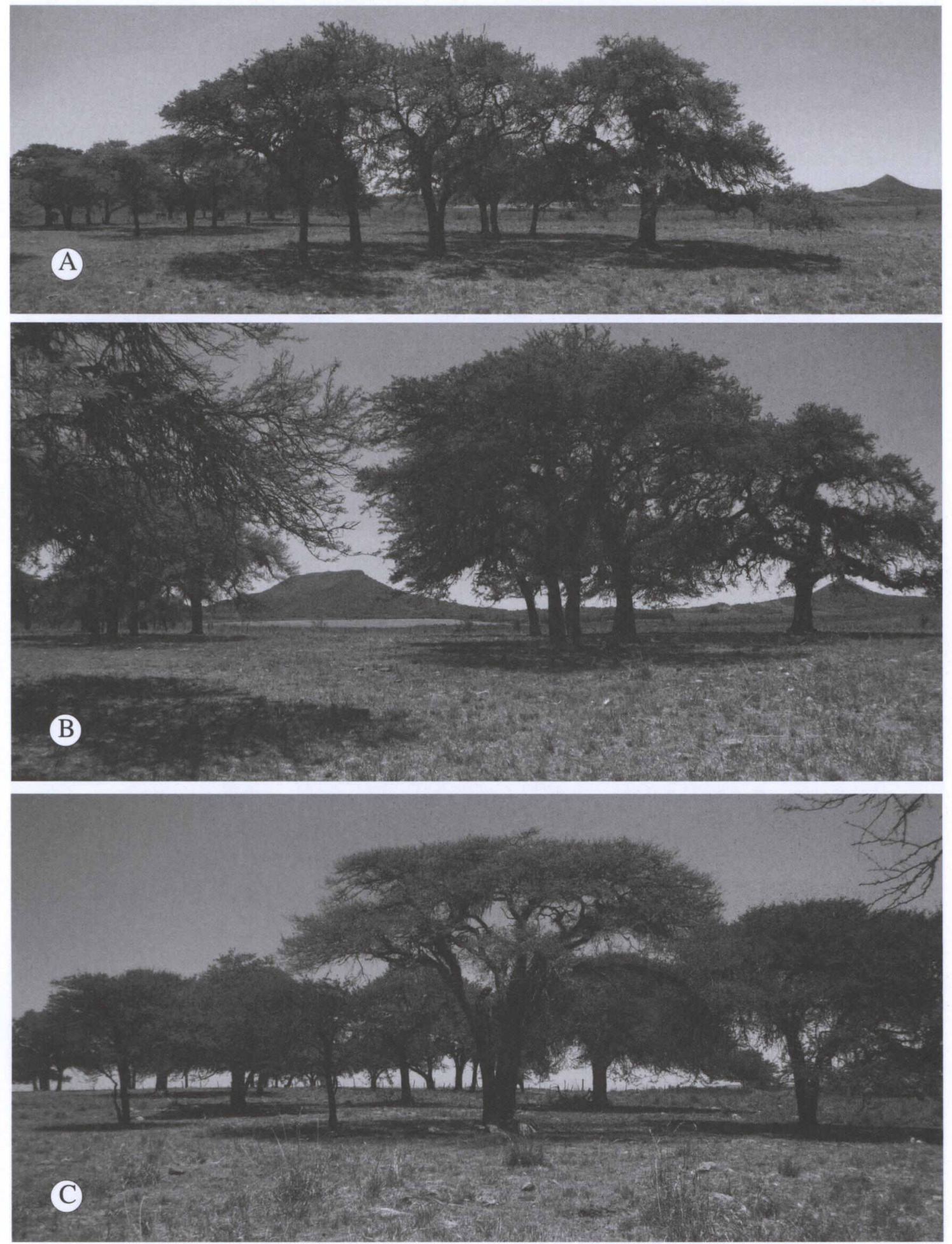

FIGURA 2 - Três aspectos do parque de Inhanduvá. A - Vista parcial, com o Cerro Batovi (Seio-de-Moça), à direita. B - Velhos inhanduvás, com o Cerro do Loreto, ao fundo. C - Aspecto parcial, destacando a estrutura inequiânea do parque. 

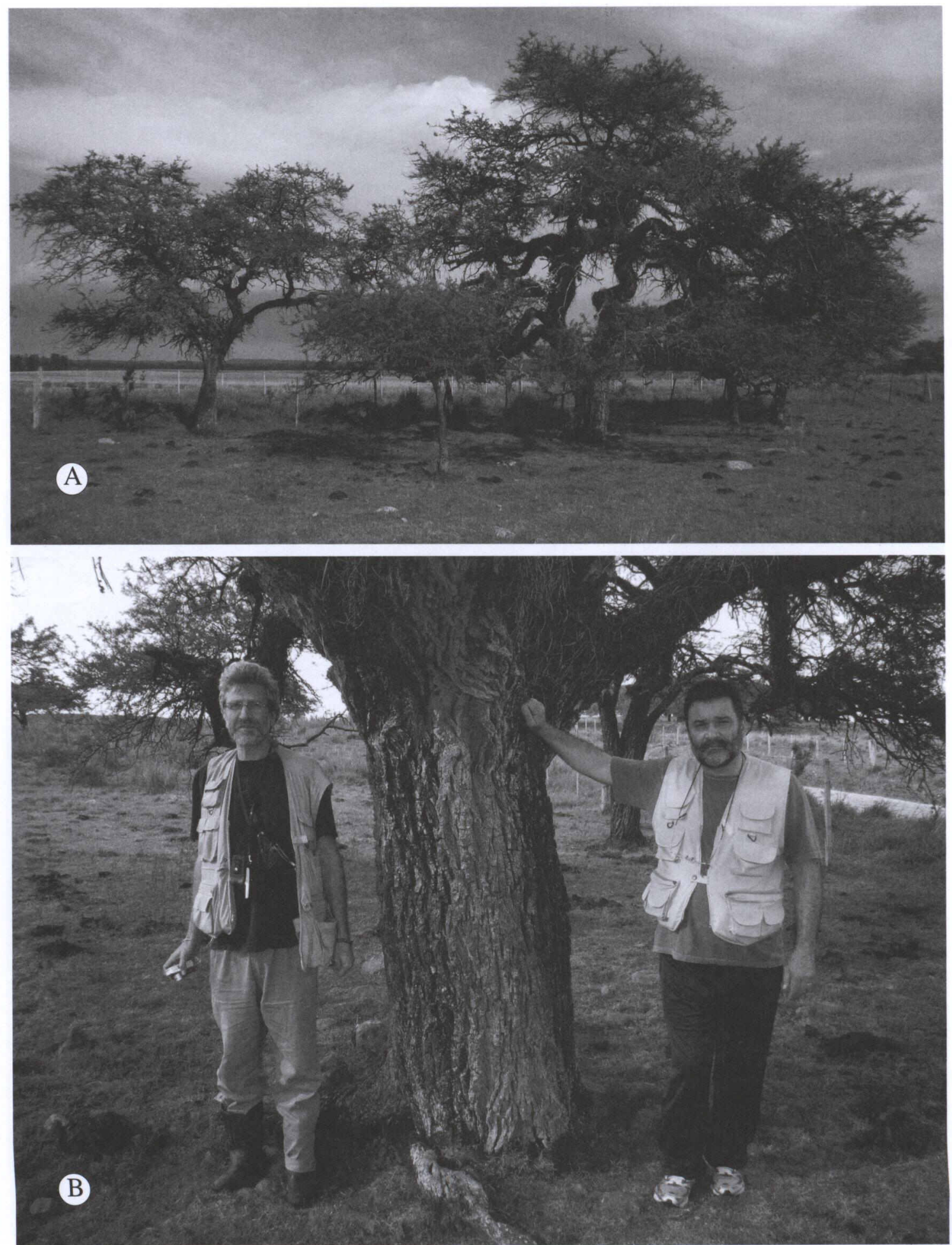

FIGURA 3 - Dois aspectos do parque de Inhanduvá. A - Estrutura tipicamente inequiânea, demonstrada por indivíduo jovem (ao centro) e um velho inhanduvá (cerca de $9 \mathrm{~m}$ ), à direita. B - Eduardo Alonso Paz (a esquerda) e José Newton Cardoso Marchiori, ladeando velho inhanduvá do parque, com cerca de $50 \mathrm{~cm}$ de DAP. 


\section{CONSIDERAÇÕES SOBRE A ORIGEM}

A ocorrência de inhanduvás em São Vicente do Sul, objeto do presente trabalho, requer análise criteriosa sob os enfoques da documentação histórica e estrutura vegetacional, com vistas à elucidação de sua origem.

Situado no topo de uma colina, a sudoeste do Cerro do Loreto e próximo aos rios Jaguari e Ibicuí, o parque em estudo não fica distante do local onde foi levantada a segunda $\mathrm{cruz}^{11} \mathrm{em}$ terras do Rio Grande do Sul, no distante ano de 1627 , e erigida uma tosca capela de pau-a-pique, coberta de palha, sob a invocação de Nossa Senhora da Candelária, obras do Padre Roque González da Santa Cruz e de índios da aldeia do cacique Tabacã ${ }^{12}$. A literatura informa que esta iniciativa pioneira teve lugar, possivelmente, na "altura da foz do rio Jaguari"13, primeiro local com população indígena numerosa encontrada por este jesuíta ao penetrar no Tape $^{14}$, desde a foz do Ibicuí no rio Uruguai.

Os índios referidos no parágrafo anterior, de língua guarani, habitavam áreas florestais e praticavam agricultura itinerante, cultivando mandioca, milho e outras plantas, em pequenas roças obtidas pela queimada de parcelas de mata nativa. Mais avançados no tocante à cultura material do que os minuanos e charruas das áreas campestres, que viviam da coleta, caça e pesca, é muito pouco provável que os guaranis, mesmo assim, tenham introduzido o inhanduvá em terras do atual município de São Vicente do Sul

\footnotetext{
${ }^{11}$ A primeira foi erigida em fins de abril ou em princípios de maio de 1626, em São Nicolau (Porto, A. História das Missões Orientais do Uruguai. Porto Alegre: Livraria Selbach, 1954. v. 1, p. 78).

${ }^{12}$ Porto, A., 1954. Op. cit., p. 78.

${ }_{13}$ Jaeger, P.L.G. Roque González, Afonso Rodríguez e João del Castillo, mártires do Caaró e Pirapó. Porto Alegre: Livraria Selbach, 1951. p. 200.

${ }^{14}$ Primeira designação atribuída às terras do atual Rio Grande do Sul. Segundo Aurélio Porto, a palavra, que significa "povoação grande", servia para designar a "dilatada região confinada pelas serras do Mar e Geral, a entestar no alto Jacuí e, pelo curso deste, até se lançar no mar" (Porto, A., 1954. Op. cit., p. 79).
}

antes do período jesuítico, uma vez que a área em questão se encontra no topo de uma coxilha, em meio a campos nativos ${ }^{15}$. Outros pontos a salientar, na refutação desta hipótese antrópica, são a falta de registro documental sobre a valorização da referida espécie arbórea, por parte dos guaranis ${ }^{16}$, bem como a grande distância que separa o parque em análise de outras áreas com vegetação semelhante, ou seja, da eventual fonte de sementes.

A região do baixo Jaguari voltou a ser palco de nova penetração jesuítica em 1632, com a fundação de São Tomé, pelos padres Pedro Romero, Noël Bertot e Luís Ernot. De vida efêmera, a redução foi abandonada em 1639, por receio das incursões bandeirantes. De acordo com Félix de Azara, ela situava-se às margens do "riachuelo Tebicuacuy" 17 , nas proximidades do rio Ibicuí ${ }^{18}$, em local não distante da área em foco. A curta existência de São Tomé, bem como os motivos apontados no parágrafo anterior, desautorizam, igualmente, a introdução do inhanduvá neste período.

${ }^{15}$ Como dito anteriormente, os guaranis valiam-se de terras florestais para seus cultivos.

${ }^{16} \mathrm{O}$ nome da árvore, mesmo assim, vem do guarani: ñandu = ema; ubáy, uváy = comida, indicando servirem os legumes desta árvore como alimento para as emas (Rhea americana). Árvore nativa do centro de Corrientes para o sul, o inhanduvá foi utilizado como madeira apenas na redução de Japejú (Schulze-Hofer, M.C.; Marchiori, J.N.C. O uso da madeira nas reduções JesuíticoGuarani do Rio Grande do Sul. Porto Alegre: IPHAN, 2008. p. 77). A utilização de sua madeira é limitada pelas características do tronco: "pero como sus ramas son tortuosas, cortas y poco gruesas, apenas sirve mas que para empalizadas y para quemar" (Azara, F. de. Viajes por la América Meridional. Madrid: Calpe, 1923a. p. 128).

17 Antigo nome do rio Jaguari; Tibiquari ou Tevicuary, em outros textos. A palavra significa "rio da região das tumbas" (tyvy = tumba, cuá = lugar, e ry = rio). O termo "riachuelo", utilizado por Don Félix de Azara, sugere tratar-se do rio Jaguari-Mirim, afluente da margem direita do rio Jaguari e que tem sua foz a curta distância da desembocadura deste rio no Ibicuí.

${ }^{18}$ Azara, F., Viajes por la América Meridional. Madrid: Calpe, 1923b. v. 2. p. 202. 
Em 1638, com o êxodo dos padres e índios para a margem direita do rio Uruguai, em terras da atual Argentina, o vale do Ibicuí viu-se despovoado dos antigos moradores (indígenas), dando lugar à recomposição natural das florestas. O gado bovino, por sua vez, que fora introduzido em 1629 pelos jesuítas, proliferou rapidamente nas áreas campestres, favorecido por abundantes pastagens e aguadas.

Ao voltarem para a margem ocidental do rio Uruguai, os padres da Companhia ${ }^{19}$ restabeleceram seu domínio com os Sete Povos das Missões e dividiram o restante das áreas campestres em grandes "estâncias" para criação de gado.

Neste "segundo ciclo jesuítico", a área em estudo integrou uma estância pertencente ao povo missioneiro de São Miguel, delimitada, perfeitamente, pelos rios Jaguari, Ibicuí, Toropi e, ao norte, pelos "alcantis da Serra Geral", onde as crônicas informam que "vagavam 30.000 cabeças" de gado ${ }^{20}$. Como estância jesuítica, ela perdurou até a expulsão dos padres, em 1767, passando à administração de funcionários espanhóis entre esta data e a "Conquista das Missões" (1801), iniciativa de um grupo de patriotas gaúchos ${ }^{21}$.

$\mathrm{Na}$ área em foco, a introdução do inhanduvá pode ser igualmente descartada neste período,

${ }^{19} \mathrm{O}$ mesmo que jesuítas ou inacianos.

${ }^{20}$ Silveira, H.J.V. da. As Missões Orientais e seus antigos domínios. Porto Alegre: Typographia da Livraria Universal de Carlos Echenique, 1909. p. 580.

${ }^{21}$ A "Conquista das Missões" ao domínio português, mais do que obra de um grupo de aventureiros, resultou de um longo processo de decadência dos Sete Povos, iniciado pela Guerra Guaranítica (1752 - 1756) e acelerado após a expulsão dos jesuítas. $\mathrm{O}$ dešfecho deu-se em 1801, quando um grupo de patriotas gaúchos, comandados por Manoel dos Santos Pedroso, atacou a Guarda de São Martinho, conquistando este ponto estratégico aos castelhanos. Na seqüência, José Borges do Canto e Gabriel Ribeiro de Almeida, à frente de 40 homens, tomaram os Sete Povos para os portugueses, definindo, com esta façanha, um litígio de fronteiras cujas origens mais remotas precedem o famoso Tratado de Tordesilhas (Marchiori, J.N.C. Esboço histórico de Jaguari. Santa Maria: Pallotti, 1999. p. 24). seja pelo objetivo distinto das estâncias jesuíticas, centrado na criação de gado, seja pelas dificuldades técnicas inerentes ao cultivo da espécie, que é de crescimento lento e requer proteção das mudas contra o pisoteio e herbivoria, por muitos anos, além do controle de gramíneas e demais ervas. Outro fator a ser lembrado reside na abundância de madeira então disponível, em matas ciliares e de encostas de montanhas, para o suprimento de uma demanda quase inexistente.

Nos primeiros anos da Revolução Farroupilha, as terras da antiga estância missioneira receberam boa parte da população indígena emigrada das antigas reduções, bem como expressivo grupo de índios missioneiros que haviam sido levados por Frutuoso Rivera em 1829 para Santa Rosa del Cuareim (atual Bella Unión), no extremo noroeste do Uruguai. Hemetério José Veloso da Silveira comenta que os índios se estabeleceram em Cavajuretã e nos arredores da vila de São Vicente, e que o governo procurou reuni-los, "dando-lhes um diretor", providências que se mostraram inúteis, porque eles se dispersavam e "vendiam à população branca os terrenos onde se arranchavam" 22 .

Sob o ponto de vista fitogeográfico, cabe lembrar que em Bella Unión, cidade separada de Barra do Quaraí pelo rio de mesmo nome, a vegetação natural compõe-se de matas ciliares e parques arbóreos, com inhanduvá e outras espécies chaquenhas. Seriam estes índios, os agentes introdutores do inhanduvá em São Vicente do Sul?

Embora plausível, em princípio, a hipótese aventada carece de comprovação, tanto em documentos como pela tradição oral. Além disso, cabe salientar que antes da vinda destes índios para o atual município de São Vicente, boa parte das terras já havia sido ocupada por estancieiros, "uns por compras feitas ao cabildo de São Miguel, outros por concessões dos comandan-

${ }^{22}$ Silveira, 1909. Op. cit., p. 580. 
tes das Missões"23. Entre os primeiros, encontra-se Luiz Carvalho da Silva, sesmeiro que adquiriu em 1810 as quatro léguas quadradas da "Estância do Loreto", onde fica o parque de inhanduvá em estudo. Não menos importante, ainda, é o testemunho de antigos moradores da região, que são unânimes ao informar que o parque de inhanduvá sempre existiu no local em que se encontra.

No capítulo dedicado a São Vicente, Hemetério José Veloso da Silveira não faz um único comentário sobre vegetação, o que é de se lastimar, posto que o autor, na condição de advogado, conheceu a pessoalmente a região no outono de 1859, em uma viagem de Cruz Alta à "estância do Loreto"24. Como justificativa para este lapso, cabe informar que, nesta época, a sede da antiga "Estância do Loreto" situava-se em ponto distante do parque de inhanduvá.

$\mathrm{Na}$ ausência de evidências histórico-documentais sobre a vegetação em foco, a investigação acerca da origem pode ser direcionada a aspectos de sua própria estrutura, bem como a características dendrológicas dos indivíduos integrantes.

Neste sentido, chama atenção, em primeiro lugar, a ausência de ordenamento no parque de inhanduvá, pois os indivíduos distribuem-se irregularmente, ao molde característico de vegetações naturais, que é muito distinto da padronização buscada pela mão humana.

O diâmetro e altura avantajados de alguns indivíduos, que ultrapassam os valores comumente encontrados na área do Parque Estadual do Espinilho ${ }^{25}$, em Barra do Quaraí, tes-

23 Silveira, 1909. Op. cit., p. 581.

${ }^{24}$ Silveira, 1909. Op. cit., p. 579.

${ }^{25}$ Criado em 12/3/1975, com área de 276 ha, pelo Decreto $n^{\circ} 23.798$, do Governo do Estado do Rio Grande do Sul. A área foi ampliada 1.617,14 ha, em 28/2/2002, mediante Decreto $n^{\circ} 41.440$, do Governo do Estado do Rio Grande do Sul. A unidade de conservação visa a preservar o fragmento mais representativo e biodiverso da Província do Espinhal (Espinal, em espanhol) no Estado. temunham sobre a idade avançada dos mesmos, depondo favoravelmente, ao mesmo tempo, sobre a antiguidade da vegetação no espaço regional. Embora claramente inequiânea, são relativamente escassas as regenerações e indivíduos jovens (diâmetro $<10 \mathrm{~cm}$ ), fato que pode ser atribuído à permanente predação e pisoteio de brotações, exercidos pelo gado. Situado no alto de uma coxilha revestida por campo nativo, os inhanduvás servem de abrigo para o gado nas horas mais quentes do dia, apesar da rala sombra que fornecem.

Comparado ao Parque Estadual do Espinilho, de Barra do Quaraí, a vegetação em estudo distingue-se, ainda, pela ocorrência de uma única espécie no estrato arbóreo - Prosopis affinis Spreng. -, assemelhando-se, neste aspecto, ao observado no parque do Jarau (Alves \& Marchiori, 2010). Comparado a este, todavia, há que salientar-se, no caso de São Vicente, a ausência de Tillandsia duratii Visiani, um cravo-do-mato de origem chaquenha, bem como da arumbeva-de-flores-alaranjadas (Opuntia elata Salm Dick).

Sobre o ponto acima comentado, resta salientar que as diferenças observadas estão de acordo com a previsível diluição de elementos chaquenhos a partir do extremo oeste do Estado: em Barra do Quaraí, a composição do estrato arbóreo, mais biodiversa, inclui o espinilho (Vachellia caven (Mol.) Seigler \& Ebinger), o algarrobo (Prosopis nigra (Griseb.) Hieron.), o quebracho (Aspidosperma quebrachoblanco Schltdl.) e a cina-cina (Parkinsonia aculeata L.). Destes, o algarrobo e o quebracho limitam-se ao parque de Barra do Quaraí, a cina-cina ocorre em todo o sudoeste do Estado, e o espinilho apresenta distribuição ainda mais ampla, alcançando o Planalto Médio, Depressão Central e Serra do Sudeste (Sobral et al., 2006).

Com relação ao inhanduvá, o presente registro de sua ocorrência natural em São Vicente do Sul, bem como na região do Jarau, descrita por Alves \& Marchiori (2010), demonstra o equívoco de Galvani (2003), ao afirmar que as 
"duas espécies de Prosopis"26 (...) "somente podem ser encontradas nas áreas mais secas, formadas por solos dos tipo Gleissolo Melânico, em áreas de maior elevação do terreno"27. Nem uma coisa, nem outra: no Rio Grande do Sul, a distribuição geográfica de Prosopis affinis não se restringe aos arredores de Barra do Quaraí; a referida espécie, por sua vez, também não está intimamente vinculada a um determinado tipo de solo, fato comprovado, cabalmente, nos parques naturais do Jarau (Quaraí) e de São Vicente do Sul.

A respeito da distribuição geográfica do inhanduvá, cabe salientar que a espécie se encontra naturalmente desde a costa norte do Peru até a Argentina, incluindo o extremo sul da Bolívia, Paraguai, além do oeste do Uruguai e Rio Grande do Sul (Izaguirre \& Beyhaut, 2003). Para a Argentina, Burkart (1987) assinala sua ocorrência no sul de Corrientes, bem como nas províncias de Entre Rios, Santa Fé, Córdoba, Chaco e Formosa, correspondendo a uma vasta área no nordeste do país vizinho. A amplitude desta distribuição geográfica é argumento suficiente para contestar a afirmativa de Galvani (2003) exposta no parágrafo anterior, pois não é concebível que em todas estas áreas de ocorrência se encontre o mesmo solo, por ele referido. No caso do Uruguai, Izaguirre \& Beyhaut (2003) informam que a espécie "habita en suelos pedregosos, praderas llanas bien evolucionadas y no erosionadas y bosques ribereños" ${ }^{28}$. Para o Rio Grande do Sul, no caso dos parques naturais do Jarau e de São Vicente do Sul, vê-se que o inhanduvá também ocorre em solos arenosos e areno-pedregosos.

A ocorrência natural do inhanduvá em São Vicente do Sul, além de disjunção notável, sinaliza um caráter relitual para a espécie, no estado do Rio Grande do Sul. A ausência ou desconhecimento de outros fragmentos com esta

\footnotetext{
${ }^{26}$ Leia-se: Prosopis affinis e Prosopis nigra.

${ }^{27}$ Galvani, 2003. Op. cit., p. 63-64.

${ }^{28}$ Izaguirre \& Beyhaut, 2003. Op. cit., p. 95.
}

vegetação ao longo do vale do rio Ibicuí justifica, por um lado, o desenvolvimento de novas pesquisas sobre o tema; a não confirmação dos mesmos, todavia, pode ser mero resultado da ação antrópica exercida em séculos de ocupação do espaço regional, posto ser bem conhecido o desfavorecimento do inhanduvá frente a espécies como o espinilho (Vachellia caven), fato demonstrado por Holleben (1969), na zona semiárida do Chile central.

\section{CONCLUSÃO}

$\mathrm{Na}$ ausência de registro histórico-documental em contrário, a estrutura do parque de inhanduvá da Cabanha do Loreto, em São Vicente do Sul, indica que a vegetação é de ocorrência natural, não sendo resultante de introdução humana.

\section{AGRADECIMENTOS}

Os autores registram sinceros agradecimentos pela generosa acolhida que receberam dos proprietários da Cabanha do Loreto, o $\mathrm{Sr}$. Rodinei Ferrari Mello e digníssima esposa.

\section{REFERÊNCIAS BIBLIOGRÁFICAS}

ALVES, F. da S.; MARCHIORI, J.N.C. O inhanduvá (Prosopis affinis Spreng.) no Rio Grande do Sul. 2 - Ocorrência natural na região do Jarau, Quaraí. Balduinia, Santa Maria, n. 25, p. 1-9, 2010.

AZARA, F. de. Viajes por la América Meridional. Madrid: Calpe, 1923a. v. 1.309 p.

AZARA, F. de. Viajes por la América Meridional. Madrid: Calpe, 1923b. v. 2. 233 p.

BURKART, A. Leguminosae (= Fabaceae), Leguminosas. In: BURKART, A.; BURKART, N.T. de; BACIGALUPO, N.M. Flora Ilustrada de Entre Rios (Argentina). Buenos Aires: I.N.T.A., 1987. p. 442-738.

GALVANI, F.R. Vegetação e aspectos ecológicos do Parque Estadual do Espinilho, Barra do Quaraí, RS. 132 f. Porto Alegre: Universidade Federal do Rio Grande do Sul, 2003. Tese de Doutorado (Programa de Pós-Graduação em Botânica). 
HOLLEBEN, G.S. von. Metodos de reforestación com espino (Acacia caven (Mol.) Hook \& Arn.) en la zona semiarida de Chile. Santiago: Universidad de Chile, 1969. 134 f. Tese de Graduación (Escuela de Ingenieria Forestal).

IZAGUIRRE, P.; BEYHAUT, R. Las leguminosas em Uruguay y regiones vecinas. Montevideo: Editorial Hemisferio Sur, 2003. 301 p.

JAEGER, P.L.G. Roque González, Afonso Rodríguez e João del Castillo, mártires do Caaró e Pirapó. Porto Alegre: Livraria Selbach, 1951. 389p.

MARCHIORI, J.N.C. Esboço histórico de Jaguari. Santa Maria: Pallotti, 1999. 183 p.

MARCHIORI, J.N.C. Fitogeografia do Rio Grande do Sul. Campos Sulinos. Porto Alegre: EST, 2004. 110 p.

MARCHIORI, J.N.C.; ALVES, F. da S. O inhanduvá (Prosopis affinis Spreng.) no Rio Grande do Sul. 1 - Embasamento fitogeográfico e pendências terminológicas. Balduinia, Santa Maria, n. 24, p. 1-11, 2010.

MARCHIORI, J.N.C.; LONGHI, S.J.; GALVÃO, L. O gênero Prosopis L. (Leguminosae Mimosoideae) no Rio Grande do Sul. Ciência e Natura, Santa Maria, n. 5, p. 171-177, 1983.

MARCHIORI, J.N.C.; LONGHI, S.J.; GALVÃO, L. Composição florística e estrutura do Parque de Inhanduvá no Rio Grande do Sul. Rev. Centro de Ciências Rurais, Santa Maria, v. 15, n. 4, p. 319-334, 1985.

PORTO, A. História das Missões Orientais do Uruguai. Porto Alegre: Livraria Selbach, 1954. v. $1.434 \mathrm{p}$.

SCHULZE-HOFER, M.C.; MARCHIORI, J.N.C. $O$ uso da madeira nas reduções Jesuítico-Guarani do Rio Grande do Sul. Porto Alegre: IPHAN, 2008. 80 p.

SILVEIRA, H.J.V. da. As Missões Orientais e seus antigos domínios. Porto Alegre: Livraria Universal de Carlos Echenique, 1909. 702 p.

SOBRAL, m.; JARENKOW, J.A.; BRACK, P.; IRGANG, B.; LAROCCA, J.; RODRIGUES, R.S. Flora arbórea e arborescente do Rio Grande do Sul, Brasil. São Carlos: RiMa : Novo Ambiente, 2006. 350 p.

STRECK, E.V.; KÄMPF, N.; DALMOLIN, R.S.D.; KLAMT, E.; NASCIMENTO, P.C. do; SCHNEIDER, P.; GIASSON, E.; PINTO, L.F.S. Solos do Rio Grande do Sul. Porto Alegre: EMATER/RS - ASACAR, 2008. 222p.

VELOSO, H.B.; GÓES-FILHO, L. Fitogeografia brasileira-Classificação fisionômico-ecológica da vegetação neotropical. Salvador: Projeto RADAMBRASIL, 1982. 80 p. (Boletim Técnico, Ser. Vegetação, v. 1). 